\title{
Updating: Cryptococcosis Diagnostic Aspects
}

Filipe A Colombo ${ }^{1}$, Rogério Brasiliense Elsemann ${ }^{2}$, Alexandre Conde ${ }^{2}$, Daniel Galafassi ${ }^{2}$ and Alexandra F Gazzoni ${ }^{*}$

${ }^{1}$ Oral Microbiology and Pathology Testing Service Laboratory, School of Dentistry, Faculdade da Serra Gaúcha, 95020-472, Caxias do Sul, Brazil

${ }^{2}$ School of Dentistry, Faculdade da Serra Gaúcha, 95020-472, Caxias do Sul, Brazil

"Corresponding author: Alexandra F. Gazzoni, Oral Microbiology and Pathology Testing Service Laboratory, School of Dentistry, Faculdade da Serra Gaúcha, Caxias do Sul, 95020-472, Brazil, Tel: 555421016006; E-mail: alexandra.gazzoni@fsg.br

Received date: September 19, 2014; Accepted date: November 24, 2014; Published date: November 28, 2014

Copyright: (c) 2014 Colombo FA, et al. This is an open-access article distributed under the terms of the Creative Commons Attribution License, which permits unrestricted use, distribution, and reproduction in any medium, provided the original author and source are credited.

\begin{abstract}
Currently, AIDS represents the most common risk factor for the development of cryptococcosis. Despite of rapid scale-up of antiretroviral therapy programs and global investement in HIV care over the past decade, the decline in incidende and mortality rates associated with cryptococcosis has not been commensurate.

This article puts into context recent diagnostics studies and morphologies - with special attention to laboratory diagnosis based on classical mycology: (a) histopathology through the histochemical techniques of hematoxilin and eosin, periodic acid-Schiff, and Grocott's silver, as well special histochemical techniques such as Mayer's mucicarmine and Fontana-Masson; (b) cultures by Sabouraud's medium, brain-heart infusion agar, canavanineglycine-bromothymol blue agar, in addition to niger seed agar medium and lysis-centrifugation blood-culturing technique; (c) serology by cryptococcal antigen test and cryptococcal antigen lateral flow assay. In this paper, we also discussed the new rapid point-of-care lateral flow assay to be used to screening HIV-infected person with CD4 counts of less than 100 cells $/ \mu \mathrm{L}$.
\end{abstract}

It is noteworthy that laboratory findings should be interpreted considering the clinical and epidemiological history of all patients. Consequently, diagnostic tools are only properly used, if the treating physician is aware of the propensity of patients to acquire a fungal infection.

Keywords: Cryptococcus, Diagnostic tests routine; Diagnostic test approval; Point-of-care lateral flow assay

\section{Introduction}

Cryptococcus has a unique history among all the fungi pathogenic to man. It was discovered almost simultaneously to exist both as a highly virulent agent of human disease and as a saprophyte in nature $[1,2]$. In 1894, was introduced an encapsulated yeast-like fungus to the world that we now call Cryptococcus.

In Germany, Busse isolated this encapsulated yeast (referred as Saccharomyces sp.) from the ulcerous tibia of a woman showing a generalized mycotic infection [2]. During the same year, the Italian Sanfelice recovered a yeast-like organism from fermenting peach juice and demonstrated to be pathogenic to dogs, guinea pigs and chicken. Because of its "tumour" - forming properties in experimental animals, the Italian named his isolate $S$. neoformans [1]. Much of pathology and the features of primary pulmonary disease were described by Baker and Haugen [3]. In 1905, Von Hansemann presented the first report of cryptococcal meningitis [4].

Over the years, the organism was reisolated and many others names were coined, including Saccharomyces hominis, Blastomyces neoformans, Cryptococcus hominis, Torula histolytica and Cryptococcus histolyticus. Synonyms for infection included tolurosis, European blastomycosis, Busse-Buschke disease and torula meningitis [5]. This created a little bit of confusion and the names Cryptococcus and cryptococcosis were finally decided upon to describe all the isolates, as well as the disease, respectively [6].

\section{Infection}

Five mayor sites of involvement important in the diagnosis and management of cryptococcosis are the lungs, CNS, skin, prostate and eyes $[7,8]$. The lungs, is invariably the portal of entry, by inhalation from an environmental source, and initial site of infections. Cryptococcus neoformans mainly causes opportunistic infections of immuncompromised patients with underlying conditions such as HIV, leukemia and other cancers as those taking corticosteroid medication. On this setting, $C$. neoformans can disseminate to other organs [9]. The organism is trophic to the CNS, and the majority of cases are related to meningitis - a condition that is fatal if left untreated $[10,11]$. All areas of the body can be infected. Extrapulmonary and extraneural manifestations are observed in about $60 \%$ of the patients. Involvement of oral cavity, liver, lymph nodes, kidneys, adrenals are considered to be manifestations of disseminated disease $[10,12]$. Serotype A (Cryptococcus neoformans var. grubii) is responsible for the majority of cryptococcosis cases in the immunocompromised host [7]. Contrary to Cryptococcus neoformans, C. gattii primarily infects otherwise healthy individuals [13]. Although both species infect the central nervous system, $C$. gattii appears to invade the brain parenchyma more commonly than $C$. neoformans [11]. Furthermore, in C. gattii infected patients, pulmonary infections are more likely and pulmonary mass-like lesions are more common than in $C$. neoformans infected patients [14]. Interestingly, the epidemiology of Cryptococcus gattii continues to evolve. The emergence of highly virulent species in immunocompetent populations, especially in northwest America and British Columbia, ensures greater awareness because delayed diagnosis 
and inappropriate antifungal therapy is associated with high mortality [15].

Thus, the epidemiology of cryptococcosis can be broadly classified into two groups: (a) an common opportunistic fungal infection, or (b) when behaves as a primary pathogen.

\section{Central nervous system infection}

To cause CNS infection, Cryptococcus must cross several epithelial and/or endothelial cell layers, first to leave the lung and them to reach the brain [8]. Although the neurotropism of this yeast has been known for more than a century, the mechanism by which fungal cells invade the central nervous system has remained elusive. The first mechanism posits a "Trojan horse" approach. According to Shi et al., fungal cells are phagocytosed first in the blood or the vicinity of the endothelial cells of the brain vasculature and then the phagocytic cells transports them to the parenchyma [16]. Circumstantial evidence for this mechanism is provided by the fact that Cryptococcus is a facultative intracellular pathogen that can survive in macrophages, and that extrapulmonary dissemination appears to be macrophages associated $[17,18]$. The second mechanism posits that naked this pathogen invade the brain by direct transcytosis of endothelial cells lining the brain vasculature. This view is supported by in vivo observations showing that yeast cells are taken up by endothelial cells and can transit through the cytoplasm to emerge on the other cellular surface. Neither mechanism is exclusive of the other or in fact, there some evidence that both can occur simultaneously [15].

The predilection of Cryptococcus for the brain has been attributed to the ability to grow at higher temperatures $\left(\geq 37^{\circ} \mathrm{C}\right)$ with genetic control of the temperature phenotype via calcineurina [19]. Several studies have demonstrated that calcineurina $\mathrm{B}$ has a central role in virulence and antifungal drug action in Cryptococcus [20,21].

A recent, retrospective clinical study of Cryptococcus infection revealed that HIV-positive patients were more likely than those without HIV infection to have CNS involvement (91.1\% versus $21.7 \%$, $\mathrm{P}<0.001)$. Of note in that study, despite the differences in CNS involvement, mortality rates for the 2 groups were not statistically significantly different $(\mathrm{P}=0.162)$ [22]. Cryptococcal infection in immunocompetent patients is rare, and CNS cryptococcomas in such patients has seldom been reported [23]. The intracranial cryptococcoma that is characterized by accumulation of Cryptococcus and inflammatory cells [24]. It is reported that patients infected with Cryptococcus gattii are more likely to develop a CNS mass [25]. This can be explained by the fact that metabolites released by Cryptococcus gattii can inhibit the migration and function of leukocytes and promote survival as well as localized replication of the pathogen, facilitating formation of cryptococcoma [26].

\section{Skin}

The skin is most common extra-neural site of dissemination [27]. The lesions may vary greatly in morphology and mimic other dermatological entitie [27,28]. They may have misdiagnosed as molluscum contagiosum and Kaposi's sarcoma [29,30]. The skin lesions may appear as acneform lesions, tumors, vesicles, plaques, abscess, cellulitis, purpura, draining sinus, ulcers, subcutaneous swelling or superficial granulomas; and the numerous umbilicated papules developing in HIV-positive patients leads to differential diagnosis of penicillosis and histoplasmosis [27,29-32]. These lesions are as ominous sign and can present months prior to others signs of systemic infections; always represents disseminated disease and are correlated with high fungal burden [32-34]. This array of cutaneous presentations emphasizes the need to biopsy and obtain appropriate histopathological sections of all new skin lesions in high-risk patients. Skin lesions with different characteristics should be individually biopsied and processed [8].

\section{Prostate}

Host defence is limited within the prostate gland, and it is a persistent site of infection following amphotericin B therapy, particularly in the immunocompromised host [35,36]. Larsen et al. refered that positive cultures of urine post-prostatic massage were found in $29 \%$ of patients in whose cryptococcal meningitis despite additional fluconazole therapy [37]. According to Barza, the treatment is complicated by the fact that the prostate is a privileged site with poor penetration by many antimicrobial agents. Relapses after therapy with fluconazole and amphotericin B and persistence of Cryptococcus in the urine and prostatic fluid of HIV-positive patients have raised concern about the efficacy of therapy at this site of infection $[35,38]$.

In careful follow-up of patients with HIV-infection, cultures of routinely urine are frequently positive at the end of therapy. Additionaly, the prostate associated with CNS infection, represents a potential reservoir of Cryptococcus that may be responsible for clinical relapse of meningitis in AIDS patients $[35,36]$. Thus, after treatment, high-risk male patients should be screened by culture of urine samples to ensure that the yeasts have been eliminated [11].

\section{Laboratory diagnosis}

In diagnostic of infectious disease, the clinican faces the dilemma that under conditions of immunosupression, most fungi are potentially pathogenic, and that diagnostic tools do not always allow a definitive diagnosis to be made. Therefore, one must start out with a high index of suspicion in making a diagnosis of fungal infections [39].

The definitive laboratory diagnosis of cryptococcosis can be made directly, by detecting the presence of the microorganism. The results of direct microscopic and histopathological examination, in addition to serological screening guide the correct interpretation of laboratory findings and initial therapeutic decision $[10,12]$. The results of cultures can corroborate or change this decision [39].

\section{Direct examination}

Direct examination is conclusive for the diagnosis of cryptococcosis $[10,39]$. Clinical specimens from the tissue and surgical wounds, aspirates from cutaneous lesions, sputum and respiratory samples to body fluids, such as blood, urine and spinal fluid should be examined by India ink preparations [11]. For a routine positive India ink test from CSF, it is estimated that the specimen needs to contain more than $103 \mathrm{CFU} / \mathrm{mL}$ of CSF [40]. This technique has the advantage of revealing the presence of a capsule, that may vary in thickness from few micrometer to a width that equals or exceeds the diameter of the cell [11]. In this preparations, the yeasts cell are usually spherical-tooval and 5 to $7 \mu \mathrm{m}$ in diameter. They tipically appear refractory with a single bud that is attached by a thin connection or without buds [41]. In addition, authors describe the identification of unusual morphologies of Cryptococcus which include pseudohyphae, germtube like structures and hyphae forming, all identified in an india ink preparations of CSF $[42,43]$. This conventional method presented 
sensivity at $94.1 \%$ and specificity at $100 \%$ [44]. On the other hand, studies with cryptococcal meningitis in northern hemisphere proved to have sensivity, which ranged from $25-50 \%$ [45]. This may be a function of the late presentation of the patients with AIDS, a higher central nervous system burden of fungal yeasts in a untreated cases or failure of laboratories to culture cryptococci when the India ink test is a negative. The India ink stain have a cost-effective approach for the use routinely in developing countries [46].

The use of calcofluor may enhance detection of fungal cells, but requires a microscope with fluorescent capability. Although calcofluor white is not specific of Cryptococcus spp., this solution can be used on respiratory and biopsy specimens; and tissue aspirates to find these yeasts quickly when they are in a reduced number within a specimen [47].

\section{Histopathologic diagnosis}

The diagnosis of a fungal disease can be established on the basis of histopathologic evidence combined with cultural evidence [39]. Fixed histopathologic specimens often may be the only available material for diagnosis either because of the lack of a fresh specimen or because the fungi in tissue are not viable at the time of diagnosis $[10,48]$. Consequently, detection of fungi in tissue and confirmation of tissue invasion are required in diagnosing many opportunistic fungal infections [49].

Histopathologic procedures are rapid and relatively inexpensive. Suscessful histopathologic diagnosis is dependent upon the adequacy of the staining procedures, the use of proper stains (special fungal stains), and the morphologic characteristics of the given fungus $[12,48]$. If the fungi present their unusual morphology can give rise to diagnostic dilemma. If morphologically typical fungi are present and the tissue sections have been satisfactorily processed, identification of the disease is made in most cases [10,12,48].

Microscopic recognition may require the use of special stains $[10,12,39,48]$. Adequate methodology is especially necessary when necrotic foci are presented [49]. In tissue with necrotic foci or calcified granulomatous foci, special stains are essential [50].

\section{Histopathological features in cryptococcosis}

Mucoid appearance in gross specimens from patients with overwhelming infection may suggest cryptococcosis [3,51-53].

On histopathology, cryptococcal lesions may exhibit widely differing amounts of inflammatory response, depending on the host and the organ $[10,50,54]$. Inflammation varies from absent to marked, generally in inverse ratio to the number of organisms [50,55]. According to Schwartz, histologic spectrum varies from minimal or no inflammatory reaction (paucireactive pattern), necrotizing infection and fibrotic or calcified nodules to granulomatous lesions (reactive pattern) [50].

The paucireactive pattern is characterized by numerous yeast forms with abundant mucin formation and with complete replacement by extracellular yeasts $[10,12]$. It's associated with destruction of the involved tissue by compression from cryptococcal mucin [10,51,52] (Figure 1A). Since, reactive pattern presents typical granuloma that is usually founded at the site of infection and is recognized as a compact aggregate of macrophages with epithelioid features and multinucleated giant cells, of both foreign-body reaction and Langerhans type. The yeasts are found in an intracellular location (phagocytozed)
[48,53,56,57] (Figure 1B). Dense granulomatous response is more common outside the central nervous system, particularly in the lung $[56,57]$. Kerkering et al. have reported that these histologic variants are thought to represent differences in both the activity and duration of the infectious process as well as the nature and extent of the host immune response [58].

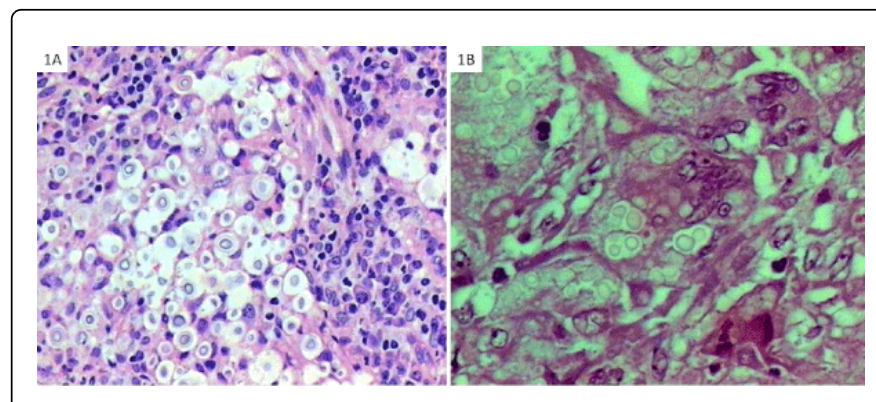

Figure 1: A) section of the lungs stained with HE. Histologic patterns of paucireactive cryptococcosis (x100). B) Reactive cryptococcosis in AIDS-associated pulmonary cryptococcosis to shows phagocytosis and giant cells of foreign body type. Of note to malformation of phagocyte an common characteristics in patients with AIDS (x40).

In the first published study, involving association of immune status with histologic features, Baker concluded that the histologic response to cryptococcosis in apparently immunocompetent patients was granulomatous, but that in immunocompromised patients there was diffuse aspect with a gelatinuos or paucireactive histology [58-60]. Findings in HIV-positive patients are even more pronounced with abundance yeasts on lung parenchyma without significant inflammation $[8,40]$. While Mayayo highlighted the importance to increase in value the immnue status of the host, since its deficit determines the degree of inflammatory response [49]. Shibuya et al. in an granuloma and cryptococcosis study, communicated that there are also other factors that influence the histology of cryptococcosis as: virulence as well as burden of microorganisms [55].

In tissue specimens sections, the typical cells are spherical, oval or ellipsoid, and surrounded by optically clear, smoothly spherical zone, or halos that are unstained capsules [12]. The size of cryptococcal cells in tissue varies widely, from 4 to $7 \mu \mathrm{m}$ in diameter (majority of the cells), not including the capsule, but cells from 2 to $15 \mu \mathrm{m}$ may occur $[10,12,48,58]$. This distinctive appearance can suggest the diagnosis strongly even on hematoxilin and eosin preparation (HE) $[3,48]$. Careful scrutiny of HE-stained slides may be necessary to see the cryptococci, but the fungus is readily seen on Grocot's silver (GMS), the cells being widely separated by spaces originally occupied by capsule [48]. The cryptococcal organisms usually are seen in singles or with one bud, but may be found in chains of budding yeasts, structures resembling germ tube, poorly encapsulated strains or as pseudohyphae [41,60] (Figure 2A). Additionally, previous reports described the cryptococccosis by non-encapsulated forms as extremely rare, and that no apparent incidence in humans [41] (Figure 2B). Nevertheless, a study with 925 cases of cryptococcal infection founded 8 cases in humans caused by capsule-deficient Cryptococcus [10]. 
Page 4 of 7

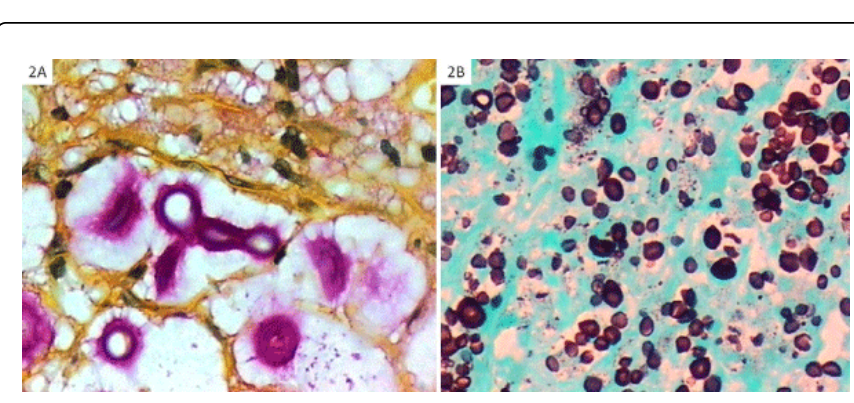

Figure 2: A) shows encapsulated budding yeasts arranged in chains. The magenta capsule are strongly stained by mucicarmine (x40). B) shows nonencapsulated cryptococci forms. Fungal cell wall is stained in black by Grocott's silver stain) (x100).

Identification of this yeast in tissue is enhanced by the use of appropriate special stains, as well as by attention to fungal morphology $[10,12,48]$. The capsule can be enhanced by staining with mucicarmine $[10,12]$. The periodic acid-Schiff/Alcian Bule stains are also applied to confirm the mucopolysacchariden capsule [61]. Sometimes fibers of red-stained mucopolysaccharide can be observed through the space surrounding the yeast cell, creating a unique appearance resembling the suspension of a spider web [60]. The magenta colour imparted to the fungal capsule is visible in nearly all lesions [12] (Figure 3A). Consequently, this yeasts may be uniformly positive by Mayer's Mucicarmine stain (MM) - except in cryptococcosis by nonencapsulated yeasts-like organisms, in which the usual colour appearance is absent $[48,52]$. As soon, the correct diagnosis of capsuledeficient cryptococci infection by using the tissue section alone may be extremely difficult $[10,48,53]$. In addition, these organisms are morphologically indistinguishable from Histoplasma capsulatum, young spherules Coccidioides immitis, small forms of Blastomyces dermatitidis and Paracoccidioides brasiliensis, Candida glabrata in tissue $[10,53]$. In this cases, as previously described, Fontana-Masson (FM) stain is useful as an alternative diagnostic, especially for distinguishing cryptococcal infection from these other fungal infections, which mimic it with their similar size and shape, tissue response and negative mucicarmine staining [48] (Figure 3B).

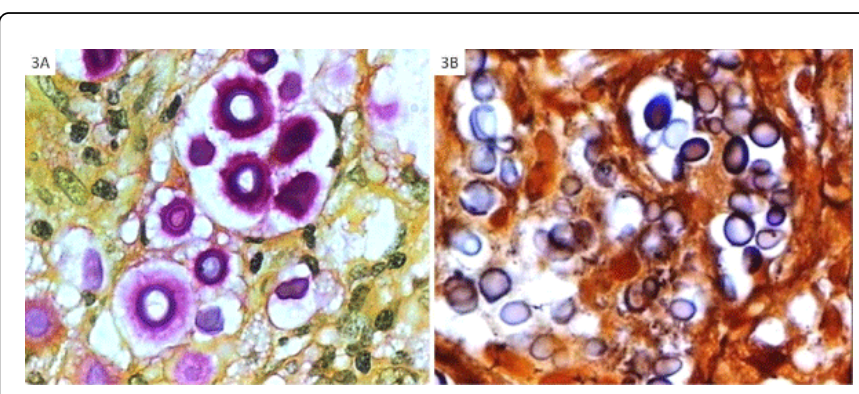

Figure 3: A) shows fungal cells presenting carminophilic capsule are intenselly stained with magenta color by mucicarmine (x100). B) section of lymph node stained with Fontana-Masson. Nonencapsulated cryptococci forms exhibited react positively for melanin fungal (x100).

\section{Cultures}

Cryptococcus grows on the majority of mycological media at $25^{\circ} \mathrm{C}$ and $35^{\circ} \mathrm{C}[39,52]$. The identification is confirmed by (a) colony morphology: by isolation of yeasts colonies with white mucoid aspect (depending on the capsule thickness) after cultivation on fungal media (within $48-72 \mathrm{~h}$ ), namely Sabouraud's $(\mathrm{SAB})$ at $25^{\circ} \mathrm{C}$, and brain-heart infusion (BHI) agar at $35^{\circ} \mathrm{C}$; (b) microscopy morphology: by demonstrating of spherical to oval encapsulated yeasts cells, budding on a narrow base and range from 2 to $20 \mu \mathrm{m}$ in diameter but usually measure $4-10 \mu \mathrm{m}$ in diameter $[12,62]$. Specimens of sputum, of pleural aspirations and bronchoalveolar lavage (BAL), CSF, skin scrapings, pus, urine or blood should be inoculated on fungal media described above [39]. In addition, its identification includes the production of a brown colony on niger seed (Guizotia abyssinica, birdseed) agar medium. This pigment is a melanin-like compound produced by the fungus with phenoloxidase activity. Additionally, use of niger seed agar is especially effective for selective identification from sputum and urine AIDS patients [38]. Interestingly, urine culture is useful in the diagnosis of disseminated cryptococcosis, even in the absence of clinical signs referable to the urinary tract, especially in AIDS patients $[63,64]$. After identity of an isolate has been established as Cryptococcus, one may proceed in determining its species status. Canavanine-glycine-bromothymol blue (CGB) agar is successfully used for this purpose. The Cryptococcus gattii is differentiated, in 1 to 5 days, by a blue color reaction when grown in CGB, whereas those of Cryptococcus neoformans do not $[10,41]$. The $C$. neoformans is also identified by urease production. This test is a rapid method to evidence urease activity by urea hydrolysis and production of ammonia. This practical screening test for presumptive identification of $C$. neoformans is simple, unaffected by $\mathrm{pH}$ changes and requires 15 minutes to be performed. No false negatives were observed by this method [65].

\section{Blood culture systems}

For blood cultures, the most sensitive method appears to be the lysis-centrifugation (LC) procedure $[8,40]$. When compared with a conventional broth cultures, the LC system has provided a higher detection rate and shorter detection time of fungemia [39,63]. Bille et al. assessed the clinical significance of earlier detection of fungemic episodes [64]. In this study, the authors reported a $36.6 \%$ increase in the detection of fungemia by the LC system as compared with the conventional method.

In Brazil, all routine blood cultures are performed by lysiscentrifugation procedure (Isolator ${ }^{\circledR}$ ) since January 1994. In this published series of progressive disseminated histoplasmosis (PDH) cases, Oliveira et al. [14] concluded that, especially, in Histoplasma capsulatum infection, the lysis-centrifugation blood culture system is gold standard for recovering these thermally dimorphic fungi. In addition, improvements in the success rate with the definitive diagnosis of the cryptococcosis, including detecting transient fungemia in self-limited acute pulmonary infection [65].

On cryptococcosis, blood culture is positive in about $10 \%$ to $30 \%$ of all patients, but is even more helpful in patients with AIDS or others immune-deficiency states $[64,65]$. Unlike of the others clinical aspects, cryptococcemia is usually associated with a poor prognosis in cryptococcal meningitis cases [66]. Consequently, Isolator should be used in cases of suspected disseminated disease due to sensitivity and reduced mean time for detection of positive culture $[64,65]$. In 
Page 5 of 7

suspected cases of bone marrow infection, if the blood cultures is done by lysis-centrifugation, the aspiration procedures is not necessary [65-69].

\section{Serodiagnosis}

The Cryptococcal Antigen (CrAg) test - devised to detect cryptococcal capsular polysaccharide antigen with the use of a Latex Agglutination (LA) kit - were first described by Bloomfield et al. [70] in the sera and CSF from a total of nine patients [67]. Currently, has become some of the most important and rapid serodiagnostic tests available of the diagnostic immumology [8,52]. The test is highly reliable for diagnosing cryptococcosis (sensitivity and specific is well above 90\%) [39]. CrAg can be detected in a wide variety of body fluids, but the LA test is only suitable for testing serum and CSF samples of predominantly human immunodeficiency virus (HIV)-positive patients [66,69]. In addition, a study with $220 \mathrm{HIV}$-positive and negative patients showed that $\mathrm{CrAg}$ testing from bronchoalveolar lavage (BAL) samples was a highly effective diagnostic technique [70]. On other hand, Gazzoni et al. [49] described that false-negative results seems to be strongly associated to a poorly encapsulated strains as the test detects at least $10 \eta \mathrm{g}$ of polysaccharide per $\mathrm{mL}$ of biological fluid and that this strain does not produce enough polysaccharide antigens to be detected by the CrAg test $[8,10]$. Noteworthy, patients with pulmonary disease without dissemination may have false-negative serum titres, since yeasts have not yet disseminated from the lungs [8]. Therefore, it's noteworthy that the serodiagnosis cannot replace the direct examination. However, both techniques are complementary for the diagnosis of cryptococcosis.

\section{Cryptococcal antigen lateral flow assay}

Recently developed point-of-care Cryptococcal Antigen tests (CrAg) used for screening for cryptococcosis among HIV-positive individuals. This tool detects the same cryptococcal polysaccharide capsule glucuronoxylomannan as the latex agglutination test [71]. The new CrAg lateral flow assay (CRAg LFA) has been cleared by US Food and Drug Administration for use in serum and cerebrospinal fluid (CSF) specimens, given its close correlation (>99\%) with the latex agglutination and enzyme immunoassay [72,73]. The assay meeting most of the WHO criteria for an ideal point-of-care test to show acceptable sensibility (70-98\%) in urine samples [72]. For detection of cryptococcosis in serum, the LFA is $95,8 \%$ to $100 \%$ sensitive when compared with CrAg and culture [74].

In a region where infrastructure is most resource-poor setting, the need for rapid and effective this screening among HIV-positive outpatients who are starting antiretroviral therapy (ART) is urgent and, if made available, has the potential to decrease mortality [71]. However, little is known of the test's characteristics in urine or whole blood in those with asymptomatic infection, as well as in infections associated to a poorly encapsulated strain or in cryptococcosis by nonencapsulated forms. Thus, this remains an area of on-going research $[71,74,75]$.

Tests for cryptococcal antibodies are not useful and are not widely available for clinical use because they have high false-positive and false-negative rates [76-79].

\section{Conclusions}

Cryptococcal disease is important cause of morbidity and mortality in severely immuno-compromised, particularly in AIDS-associated cryptococcal meningitis. Of note the reasons for this high mortality rate are multifactorial including late HIV presentation, ART treatment failure and mainly delays in diagnosis. It has been largely accepted that defence mechanism against cryptococci may vary among individuals, depending on the fungal species, tissues involved and immune status of the host. Given these considerations, we wish to emphasize the usefulness of laboratory diagnosis based on classical mycology, because allows more detailed information of an extremely complex interaction between the causative yeast and tissue response. In addition, given the high morbidity and mortality of cryptococcal meningitis, further studies are needed on how to best implement the novel test into existing ART programmes and diagnostic algorithms.

\section{Acknowledgments}

This study was supported by the Conselho Nacional de Desenvolvimento Científico e Tecnológico, CNPq (CNPq, Brazil) grant 4820521/2011-2 and Fundação de Amparo a Pesquisa do estado do Rio Grande do Sul (FAPERGS) (FAPERGS, Brazil), grant 0690-2551/14-0.

\section{References}

1. Sanfelice F (1894) Contributo alla morfologia e biologia dei blastomiceti che si sviluppano nei suchhi di alcuni frutti. Ann Ig 4: 463-95.

2. Busse O (1894) Über parasitäre zelleinschlüsse und ihre züchtung. Zentralbl.J Bacteriol 16: 175-180.

3. Baker RD, Haugen RK (1955) Tissue changes and tissue diagnosis in cryptococcosis; a study of 26 cases. Am J Clin Pathol 25: 14-24.

4. Hansemann DV (1905) Über eine bisher nicht beobachtete Gehirner Krankung durch Hefen. Verh Dtsch Ges Pathol 9: 21-4.

5. Benham RW (1950) Cryptococcosis and blastomycosis. Ann N Y Acad Sci 50: 1299-1314.

6. Ajello L (1958) Occurrence of Cryptococcus neoformans in soils. Am J Hyg 67: 72-77.

7. Carroll SF, Guillot L, Qureshi ST (2007) Mammalian model hosts of cryptococcal infection. Comp Med 57: 9-17.

8. Casadevall A, Perfect JR. Cryptococcus neoformans. Washington, ASM Press, 1998.

9. Dromer F, Mathoulin-Pélissier S, Fontanet A, Ronin O, Dupont B, et al. (2004) Epidemiology of HIV-associated cryptococcosis in France (1985-2001): comparison of the pre- and post-HAART eras. AIDS 18: 555-562.

10. Gazzoni AF, Severo CB, Salles EF, Severo LC (2009) Histopathology, serology and cultures in the diagnosis of cryptococcosis. Rev Inst Med Trop Sao Paulo 51: 255-259.

11. Mitchell TG, Perfect JR (1995) Cryptococcosis in the era of AIDS--100 years after the discovery of Cryptococcus neoformans. Clin Microbiol Rev 8: 515-548.

12. Gazzoni AF, Severo CB, Barra MB, Severo LC (2009) Atypical micromorphology and uncommon location of cryptococcosis: a histopathologic study using special histochemical techniques (one report a case). Mycopathologia 167: 197-202.

13. Severo LC de Mattos Oliveira F, Londero AT (1999) Cryptococcosis due to Cryptococcus neoformans var. gattii in Brazilian patients with AIDS. Report of three cases. Rev Iberoam Micol 16: 152-154.

14. Oliveira Fde M, Severo CB, Guazzelli LS, Severo LC (2007) Cryptococcus gattii fungemia: report of a case with lung and brain lesions mimicking radiological features of malignancy. Rev Inst Med Trop Sao Paulo 49: 263-265. 
15. Desalermos A, Kourkoumpetis TK, Mylonakis E (2012) Update on the epidemiology and management of cryptococcal meningitis. Expert Opin Pharmacother 13: 783-789.

16. Shi M, Li SS, Zheng C, Jones GJ, Kim KS, et al. (2010) Real-time imaging of trapping and urease-dependent transmigration of Cryptococcus neoformans in mouse brain. J Clin Invest 120: 1683-1693.

17. Feldmesser M Kress Y, Novikoff P, Casadevall A (2000) Cryptococcus neoformans is a facultative intracellular pathogen in murine pulmonary infection. Infect Immun 68: 4225-4237.

18. Chang YC, Stins MF, McCaffery MJ, Miller GF, Pare DR, et al. (2004) Cryptococcal yeast cells invade the central nervous system via transcellular penetration of the blood-brain barrier. Infect Immun 72: 4985-4995.

19. Odom A, Del Poeta M, Perfect J, Heitman J (1997) The immunosuppressant FK 506 and its nonimmunosuppressive analog L-685,818 are toxic to Cryptococcus neoformans by inhibition of a common target protein. Antimicrob Agents Chemother 41: 156-161.

20. Odom A, Muir S, Lim E, Toffaletti DL, Perfect J, et al. (1997) Calcineurin is required for virulence of Cryptococcus neoformans. EMBO J 16: 2576-2589.

21. Fox DS, Cruz MC, Sia RA, Ke H, Cox GM, et al. (2001) Calcineurin regulatory subunit is essential for virulence and mediates interactions with FKBP12-FK506 in Cryptococcus neoformans. Mol Microbiol 39: 835-849.

22. Jongwutiwes U, Sungkanuparph S, Kiertiburanakul S (2008) Comparison of clinical features and survival between cryptococcosis in human immunodeficiency virus (HIV)-positive and HIV-negative patients. Jpn J Infect Dis 61: 111-115.

23. Li Q, You C, Liu Q, Liu Y (2010) Central nervous system cryptococcoma in immunocompetent patients: a short review illustrated by a new case. Acta Neurochir (Wien) 152: 129-136.

24. Dubey A, Patwardhan RV, Sampth S, Santosh V, Kolluri S, et al. (2005) Intracranial fungal granuloma: analysis of 40 patients and review of the literature. Surg Neurol 63: 254-260.

25. Mitchell DH, Sorrell TC, Allworth H, Health CH, McGregor AR, et al. (1995) Cryptococcal disease of the $\mathrm{CN}$ in immunocompetent hosts: influence of cryptococcal variety on clinical manifestations and outcome. Clin Infect Dis 20: 611-616.

26. Wright L, Bubb W, Davidson J, Santangelo R, Krockenberger M, et al. (2002) Metabolites released by Cryptococcus neoformans var neoformans and var. gattii differentially affect human neutrophil function. Microbes Infect 4:1427-1438.

27. Piérard GE, Piérard-Franchimont C, Estrada JA, Rurangirwa A, Dosal FL (1990) Cutaneous mixed infections in AIDS. Am J Dermatopathol 12: 63-66.

28. Yantsos VA, Carney J, Greer DL (1994) Review of the morphological variations in cutaneous cryptococcosis with a new case resembling varicella. Cutis 54: 343-347.

29. Murakawa GJ, Kerschmann R, Berger T (1996) Cutaneous Cryptococcus infection and AIDS. Report of 12 cases and review of the literature. Arch Dermatol 132: 545-548.

30. Cockerell CJ (1995) Cutaneous fungal infections in HIV/AIDS. J Int Assoc Physicians AIDS Care 1: 19-23.

31. Maniar JK, Chitale AR, Miskeen A, Shah K, Maniar A (2005) Penicillium marneffei infection: an AIDS-defining illness. Indian J Dermatol Venereol Leprol 71: 202-204.

32. Chipungu GA, Christians SJ, Oliver SP (2008) Cutaneous cryptococcosis erroneously diagnosed as Histoplasma capsulatum infection. S Afr Med J 98: 85-86.

33. Christianson JC, Engber W, Andes D (2003) Primary cutaneous cryptococcosis in immunocompetent and immunocompromised hosts. Med Mycol 41: 177-188.

34. Thomas I, Schwartz RA (2001) Cutaneous manifestations of systemic cryptococcosis in immunosupressed patients. J Med 32: 259-266.
35. Barza M (1993) Anatomical barriers for antimicrobial agents. Eur J Clin Microbiol Infect Dis 12 Suppl 1: S31-35.

36. Staib F, Seibold M, L'age M, Heise W, Skörde J, et al. (1989) Cryptococcus neoformans in the seminal fluid of an AIDS patient. A contribution to the clinical course of cryptococcosis. Mycoses 32: 171-180.

37. Larsen RA, Bozzette S, McCutchan JA, Chiu J, Leal MA, et al. (1989) Persistent Cryptococcus neoformans infection of the prostate after successful treatment of meningitis. California Collaborative Treatment Group. Ann Intern Med 111: 125-128.

38. Finley RW, Cleary JD, Goolsby J, Chapman SW (1995) Fluconazole penetration into the human prostate. Antimicrob Agents Chemother 39: 553-555.

39. Xavier MO, Oliveira Fde M, Severo LC (2009) Chapter 1: laboratory diagnosis of pulmonary mycoses. J Bras Pneumol 35: 907-919.

40. Perfect JR, Casadevall A (2002) Cryptococcosis. Infect Dis Clin North Am 16: 837-874, v-vi.

41. Kwon-Chung KJ, Bennett JE (1992) Medical Mycology. Lea \& Febiger, Philadelphia.

42. Bava J, Solari R, Isla G, Troncoso A (2008) Atypical forms of Cryptococcus neoformans in CSF of an AIDS patient. J Infect Dev Ctries 2: 403-405.

43. Paschoal RC, Melhem MSC, Guellii T (2007) Células atípicas de Cryptococcus neoformans var. neoformans observadas em líquido cefalorraquidiano. Rev Inst Adolfo Lutz 66: 78-80.

44. Sow D, Tine RC, Sylla K, Djiba M, Ndour CT, et al. (2013) Cryptococcal meningitis in Senegal: epidemiology, laboratory findings, therapeutic and outcome of cases diagnosed from 2004 to 2011. Mycopathologia 176:443-9.

45. Chuck SL, Sande MA (1989) Infections with Cryptococcus neoformans in the acquired immunodeficiency syndrome. N Engl J Med 321: 794-799.

46. McCarthy KM, Morgan J, Wannemuehler KA, Mirza SA, Gould SM, et al. (2006) Population-based surveillance for cryptococcosis in an antiretroviral-naive South African province with a high HIV seroprevalence. AIDS 20: 2199-206.

47. Hageage GJ, Harrington BJ (1984) Use of calcofluor white in clinical mycology. Lab Med 15: 109-12.

48. Sow D, Tine RC, Sylla K, Djiba M, Ndour CT, et al. (2013) Cryptococcal meningitis in Senegal: epidemiology, laboratory findings, therapeutic and outcome of cases diagnosed from 2004 to 2011. Mycopathologia 176: 443-449.

49. Gazzoni AF, Pegas KL, Severo LC (2008) Histopathological techniques for diagnosing cryptococcosis due to capsule-deficient Cryptococcus: case report. Rev Soc Bras Med Trop 41: 76-78.

50. Mayayo Artal E (2004) Histopathological diagnosis of mycoses. Rev Iberoam Micol 21: 1-9.

51. Schwartz DA (1988) Characterization of the biological activity of Cryptococcus infections in surgical pathology. The budding index and carminophilic index. Ann Clin Lab Sci 18: 388-97.

52. Grocott RG (1955) A stain for fungi in tissue sections and smears using Gomori's methenamine-silver nitrate technic. Am J Clin Pathol 25: 975-979.

53. Severo CB, Xavier MO, Gazzoni AF, Severo LC (2009) Cryptococcosis in children. Paediatr Respir Rev 10: 166-171.

54. Travis WD, Colby TV, Koss MN, Rosado-de-Christenson ML, Muller NL, et al. (2002) Non-Neoplastic disorders of the lower respiratory tract. Washington: American Registry of Pathology 600-605.

55. Littman ML, Zimmerman LE (1956) Cryptococcosis. Grune \& Stratton, New York \& London.

56. Shibuya K, Hirata A, Omuta J, Sugamata M, Katori S, et al. (2005) Granuloma and cryptococcosis. J Infect Chemother 11: 115-122.

57. Shibuya K, Coulson WF, Wollman JS, Wakayama M, Ando T, et al. (2001) Histopathology of cryptococcosis and other fungal infections in 
patients with acquired immunodeficiency syndrome. Int J Infect Dis 5: 78-85.

58. Shibuya K, Coulson WF, Naoe S (2002) Histopathology of deep-seated fungal infections and detailed examination of granulomatous response against cryptococci in patients with acquired immunodeficiency syndrome. Nihon Ishinkin Gakkai Zasshi 43: 143-151.

59. Kerkering TM, Duma RJ, Shadomy S (1981) The evolution of pulmonary cryptococcosis: clinical implications from a study of 41 patients with and without compromising host factors. Ann Intern Med 94: 611-616.

60. Baker RD (1976) The primary pulmonary lymph node complex of crytptococcosis. Am J Clin Pathol 65: 83-92.

61. Srinivasan R, Gupta N, Shifa R, Malhotra P, Rajwanshi A, et al. (2010) Cryptococcal lymphadenitis diagnosed by fine needle aspiration cytology: a review of 15 cases. Acta Cytol 54: 1-4.

62. Adam P, Sobek O, Dolezil D, Lodin Z, Kasík J, et al. (2009) Cryptococcal meningitis--a follow-up study of a serious clinical entity: quick cytological and microbiological diagnostics using a special staining procedure in cerebrospinal fluid specimens. Folia Microbiol (Praha) 54:567-8.

63. Chandler FW, Watts JC (1997) Cryptococcosis. Pathology of infectious diseases, Stamford, Appleton \& Lange, 989-997, 1997.

64. Staib F, Seibold M (1989) Use of the membrane filtration technique and Staib agar for the detection of Cryptococcus neoformans in the urine of AIDS patients - a contribution to diagnosis, therapy and pathogenesis of cryptococcosis. Mycoses 32: 63-72.

65. Denning DW, Stevens DA, Hamilton JR (1990) Comparison of Guizotia abyssinica seed extract (bird seed) agar with conventional media for selective identification of Cryptococcus neoformans in patients with acquired immunodeficiency syndrome. J Clin Microbiol 28: 2565-67.

66. Souza HLK, Costa CR, Fernandes Ode F, Abrão FY, Silva TC, et al. (2013) Clinical and microbiological features of cryptococcal meningitis. Rev Soc Bras Med Trop 46: 343-347.

67. Bille J, Edson RS, Roberts GD (1984) Clinical evaluation of the lysiscentrifugation blood culture system for the detection of fungemia and comparison with a conventional biphasic broth blood culture system. J Clin Microbiol 19: 126-128.

68. Oliveira FM, Fernandes SS, Severo CB, Guazzelli LS, Severo LC (2007) Histoplasma capsulatum fungemia in patients with acquired immunodeficiency syndrome: detection by lysis-centrifugation bloodculturing technique. Rev Inst Med Trop Sao Paulo 49: 135-138.
69. Pasqualotto AC, Bittencourt Severo C, de Mattos Oliveira F, Severo LC (2004) Cryptococcemia. An analysis of 28 cases with emphasis on the clinical outcome and its etiologic agent. Rev Iberoam Micol 21: 143-146.

70. Bloomfield N, Gordon MA, Elmendorf DF (1963) Detection of Cryptococcus Neoformans Antigen in Body Fluids by Latex Particle Agglutination. Proc Soc Exp Biol Med 114: 64-67.

71. Tanner DC, Weinstein MP, Fedorciw B, Joho KL, Thorpe JJ, et al. (1994) Comparison of commercial kits for detection of cryptococcal antigen. J Clin Microbiol 32: 1680-1684.

72. Lin TY, Yeh KM, Lin JC, Wang NC, Peng MY, et al. (2009) Cryptococcal disease in patients with or without human immunodeficiency virus: clinical presentation and monitoring of serum cryptococcal antigen titers. J Microbiol Immunol Infect 42: 220-226.

73. Baughman RP, Rhodes JC, Dohn MN, Henderson H, Frame PT (1992) Detection of cryptococcal antigen in bronchoalveolar lavage fluid: a prospective study of diagnostic utility. Am Rev Respir Dis 145: 1226-1229.

74. Magambo KA, Kalluvya SE, Kapoor SW, Seni J, Chofle AA, et al. (2014) Utility of urine and serum lateral flow assays to determine the prevalence and predictors of cryptococcal antigenemia in HIV-positive outpatients beginning antiretroviral therapy in Mwanza, Tanzania. J Int AIDS Soc 17: 19040-19046.

75. Jarvis JN, Percival A, Bauman S (2011) Evaluation of a novel point-ofcare cryptococcal antigen testo $\mathrm{n}$ serum, plasma and urine from patients with HIV-associated cryptococcal meningitis. Clin Infect Dis 53: 1019-1023.

76. Lindsley MD, Mekha N, Baggett HC, Surinthong Y, Autthateinchai R, et al. (2011) Evaluation of a newly developed lateral flow immunoassay for the diagnosis of cryptococcosis. Clin Infect Dis 53: 321-325.

77. Manabe YC Nonyane BA, Nakiyingi L, Mbabazi O, Lubega G, et al. (2014) Point-of-care lateral flow assays for tuberculosis and cryptococcal antigenuria predict death in HIV infected adults in Uganda. PLoS One 9: e101459.

78. Kabanda T, Siedner MJ, Klausner JD, Muzoora C, Boulware DR (2014) Point-of-care diagnosis and prognostication of cryptococcal meningitis with the cryptococcal antigen lateral flow assay on cerebrospinal fluid. Clin Infect Dis 58: 113-116.

79. Dhana A (2013) Diagnosis of Cryptococcosis and Prevention of Cryptococcal Meningitis Using a Novel Point-of-Care Lateral Flow Assay. Case Rep Med 640216. 